\title{
Single incision endoscope-assisted surgery for sagittal craniosynostosis
}

\author{
James Tait Goodrich ${ }^{1,2}$
}

Received: 10 August 2016 / Accepted: 19 August 2016/Published online: 27 January 2017

(C) Springer-Verlag Berlin Heidelberg 2016

The authors have presented a paper on endoscopic assisted strip craniectomies with a "novel" innovation of using a single incision. This paper provoked me to ask where are we going with the strip craniectomies. The request to provide an editorial on this paper arrived on my desk shortly after several meetings around the world in which I heard a number of various technical "strip" modifications being offered for the treatment of craniosynostosis. I have to admit I have again become more confused and totally baffled at what the "strippers" out there are doing in the sense of unification of a theme of surgical treatment. Why do I say this? Well, it has become quite clear that there is absolutely no consensus on what works and what does not in the technical challenges to "endoscopically assisted" surgery. As I have surveyed now, nearly a hundred national and international meetings, it has become very clear that there is no one way nor is there even close to one or two or three ways or more to take a child's head apart using a tool that is conceptually more important to the surgery than the thinking that goes into the operation.

Some background on the strip craniectomy-introduced in the 1880 s, discarded in late 1890 s due to wrong treatments and high mortality — we have to thank Abraham Jacobi, MD, a pediatrician in New York for shutting down the surgical workshops of some evil surgeons for doing inappropriate craniectomies. Strippers came back again in the 1940s with Donald Matson and Frank Ingraham introducing again the

James Tait Goodrich

James.Goodrich@Einstein.yu.edu

1 Leo Davidoff Department of Neurological Surgery, Albert Einstein College of Medicine, Children's Hospital at Montefiore, Bronx, NY, USA

2 Division of Pediatric Neurosurgery, Children's Hospital at Montefiore, 111 East 210th Street, Bronx, NY 10467, USA strips but this time now adding silicone wrappers and metal clips to the craniectomy edges. This last technique is what I learned during my residency. It was a procedure that I quickly discarded, as the results were dismal and very unpredictable. I rapidly adopted the cranial vault remodeling techniques designed by Danny Marchac, Paul Tessier, Fernando OrtizMonestario, and others. I was also taught in the 1970s that a fused suture was a secondary phenomenon and not the primary problem. Thereby, just focusing on the suture was not only wrong but also leads two generations of surgeons to offer an ineffective surgical option. In the 1990s, neurosurgeons became focused on a "tool" as the golden guidance that was to solve the earlier issues and bad outcomes. But a certain group was smart enough to realize that the strips did not work unless assisted with a 2000-year old technique of using an intentional cranial molding device affectionately known as an "orthotic molding helmet." What has left me so confused is I go to a meeting and discover that some people are not using helmets under the assumption that they are not necessary and yet continue to claim good results. Even more confusing is a group has now advocated that surgery is not even needed-just put on a helmet and the child will get better, no need to strip. A more important issue is the timing of helmet in how long it needs to stay on. The mavens in this business now comment that they have not been happy with some of their outcomes and hence are now leaving the helmets on for up to 18 months. That leaves me to ask the obvious question. What was done with those children with the poorer outcomes? So at this point, if I was a young trainee, I would be quite confused as to what to do: use a helmet, for how long, or not use one at all.

I have just returned from a postgraduate education course in Europe sponsored by the ESPN with an attendance of over 100 trainees, some quite senior. One of the sessions dealt with craniosynostosis and with arguments offered by the "vaulters" versus the "strippers." The vaulters were currently using 
standardized techniques introduced first by Tessier in 1960s and further refined by Danny Marchac and Dominique Renier among others. The strippers had many variations on their theme including just taking the strip; some added barrel stave osteostomies, some took out wedges of bone, some put in springs, and some reshaped the prominent inion while some left it along. And again, there was totally no consensus on the helmet; you either liked it or you did not, and everyone had his/her own timeline as to length of use. What was even more disturbing to me was the follow-up on these patients. Most would see the patients till the helmet therapy was done, and in some cases, some follow out for a year. It was the rare exception that the team was following these patients into the school years and none into the teenage years. So again, it became rapidly clear that the long-term follow-ups were deemed not necessary. This is clearly also evident in the literature as in almost all papers on this subject; there is only a follow-up shown shortly after the surgery, typically months to a couple of years. Even surgeons who have been doing the strip operation for some years rarely put in a photo of a child greater than 4 to 5 years old. Why do I make this observation? A child operated on at 3 months of age is going to naturally undergo some dramatic growth changes up into the teenage years. Thirty five years in this business, myself and many others, early on learned there are three points of relapses in craniectomies: first 6 months postop, school age, i.e., around 4 to 5 years of age and again at the beginning of the teenage years. If you are not following these patients this far, you are doing a serious disservice to your patient and to yourself. You all belong in that category that Abraham Jacobi called "non nocere," 1894.

So, as I go back and analyze this paper again, the same questions come up. Do you need a helmet or do you not? These authors feel you do but their follow-up is very short. Do they keep the helmets on very long? In the surgical description, they do not do any barrel staving or perform lateral wedge cuts to assist in the correction, which doctors who have been practicing for decades clearly insist you have to do it to keep the correction. There is also no discussion on how long these authors will be following these patients, but my impression is likely a year or less.

A 3- to 4-month child is a very fragile eco system. These children not uncommonly can have cardiac issues like PFOs and DA. Because of the maturing hematological system, DIC is a significant issue in this very young age group which begs the question as follows: why are not serious morbidities and mortalities being reported? I have come to realize most have remained unreported by routinely asking young trainees about their programs and the techniques being used. It disturbs me greatly how often I hear of unreported deaths and also severe morbidities in the strip craniectomies. The other disturbing answer is "yes we were doing them but the 'prof' gave it up because the outcomes were not that good."

The other question I keep asking is about the bone regrowth at the strip site. I am told that in strip procedures, it is now very common to "burn the bone edges until it is "black and charred" as this reduces the postop bleeding. How can these defects fill in when the bone is "charred and burnt," and how do you know this presumed healing is the case if you are not following up these children? In my experience "charred and burnt" bone heals very poorly, if it does at all. I have recently had two adult male patients in their 30's who had strip craniectomies as infants for scaphocephaly. Both wanted to have hair implants and the dermatologist, knowing of the history, requested consultation. In both cases, CTs showed persistent bone defects and as a result, implants were not recommended. Also, of note, both patients had "nicknames" growing up due to their persistent scaphocephalic head shapes. I also recently realized that to find papers dealing with these stripper defects, which are rarely reported in the craniectomy lecture, it was best to search the literature for cranioplasty; doing this, I found an unusually high number of papers dealing with techniques for repairing defects left over from strip craniectomy.

While it would appear I am zeroing in on these authors rather aggressively, that is only partially the case. It would behoove the strippers to be more meticulous in their details and follow-ups. Antidotal one-year follow-ups are not satisfactory. There is a reason the "strip" surgical procedure has now come and gone three times over the last century. I personally do not feel a "tool" has even come close to answering this question. The use of helmets remains so variable in the treatment; I personally have not been able to follow the rationale of their use or no use at all. The stripper is confusing to follow; it is based on the use of a "tool." The use of helmets remains from none to the extreme use of 18 months, which seems to me extremely cruel to the child. And by the way, where is the literature on the deaths, the severe morbidities, and even more worrisome, the lack of long-term follow-up. Sorry but follow-ups of less than 12-15 years just does not cut it. So, as I have often commented, "a fool with a tool is still a fool." or put another way: "Men are more important than tools. If you don't believe so, put a good tool into the hands of a poor workman"- John J. Bernet, American railroad executive.

\section{Compliance with ethical standards}

Conflict of interest No COI in regards to this paper. 